Anthony Lobo:

\title{
4th National Cyber Security Workshop, 11-12 Nov 2016, Mumbai
}

http://www.ewh.ieee.org/r10/india council/CyberSecurity/4thCyberWorkshop2016/

\section{Abstract:}

The $4^{\text {th }}$ National Cyber Security Workshop organised by IEEE India Council was held in Mumbai at the sprawling Yantra Park, Thane Campus of Tata Consultancy Services on 11 \& 12 November, 2016. This event follows two successful editions of the workshop in Ahmedabad (2013) and Bangalore (2014 \& 2015).

\section{Agenda:}

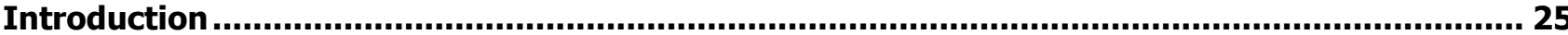

Sessions

\section{Author:}

Mr. Anthony Lobo

Formerly Advisor - Corporate Social Responsibility Tata Consultancy Services Limited, Mumbai, Presently Chair IEEE Bombay Section, anthonylobo@ieee.org 


\section{Introduction}

An impressive line-up of domain experts took the participants through the minefield of security issues in the cyber world covering computing, telecom, finance, automotive, law enforcement, SCADA and allied applications.

\section{Sessions}

The sessions were interactive and down to earth and the speakers included computer scientists, security experts, the CISO of a mobile service provider along with an advocate specialised in cyber law, all of who shared an insider's view with the participants over two days.

- Cyber Security for Financial Transactions - Issues and Countermeasures MR NANDKUMAR SARAVADE, Officer on Special Duty, Reserve Bank of India

- Information Security in an Enterprise : A Reckoner MR BRIJESH DATTA, SVP and CISO, Reliance Jio Infocomm

- Cyber security of industrial control systems DR ZIA SAQUIB, Executive Director, C-DAC

- Cyber Laws and Crimes ADV VICKY SHAH, Advocate Information Security \& Cyber Law

- Threat perception and attack scenarios in automotive environment PROF S K SINHA, Professor (Retd) Indian Institute of Science, Bangalore

- Web Security DR R K SHYAMASUNDAR, Senior Professor TIFR, Mumbai

- Internet of Things (IoT) Security MR AVINASH KADAM, ISACA IDRBT

- Hardware Intrusion: A Silent Enemy DR ANIL K ROY, Faculty, DA-IICT, Gandhinagar

Joining the participants at the venue were over 100 online participants who were also able to interact with the expert speakers.

An added attraction was the offer of ISACA's "CSX Career Starter" training material provided gratis to all registrants. This comprised their Cybersecurity Fundamentals Study Guide together with an attractive discount on the ISACA Cybersecurity certification programme. The Workshop provided a very timely insight into the intricacies of the internet, which on one side offers boundless opportunities for information sharing, commerce and connectivity yet posing the challenges of data theft, criminal hacking, invasion of privacy, and boundaries of monitoring by supervising agencies. The event was organised by Dr Amit Kumar and Dr Anil Roy of IEEE India Council. 